Daniel Dzikiewicz ${ }^{1}$

Vilniaus šv. Juozapo kunigų seminarija, Lietuva

Teologinis Institutas

\title{
Die Prinzipien der katholischen biblischen Hermeneutik in ,der Sprache der Unmündigen“. Ein Beitrag zum 25. Jubiläum des Dokumentes der Päpstlichen Bibelkommission zur Interpretation der Bibel in der Kirche
}

\section{Vorwort}

Die ältesten Texte der Menschheit, welche ungefähr aus der zweiten Hälfte des IV. Jahrtausends vor Christus stammen, wurden bei Ausgrabungen im XIX. Jahrhundert an verschiedenen Orten Mesopotamiens aufgefunden. Laut Meinung der Wissenschaftler begann dort nämlich die grossartige Geschichte des Schrifttums². Warum wurde eigentlich dieses Gebiet zum Vaterland der Literatur? Die Ursache dessen liegt in der Erfindung unterschiedlicher neuer Technologien und ihre

\footnotetext{
${ }^{1}$ Daniel Dzikiewicz (geb. 1971) — Priester aus dem Bistum Vilnius, Litauen; Dozent am Theologischen Institut des Seminars des hl. Josefs in Vilnius; Bachelor der Theologie: Fakultät der Katholischen Theologie an der Vytautas Magnus Universität in Kaunas, Litauen (1995); Lizenziat der biblischen Theologie: Päpstliche Gregorianische Universität in Rom, Italien (2003); Doktorat der biblischen Theologie: Päpstliche Theologische Fakultät in Breslau, Polen (2014); e-mail: ddz12b@gmail.com. ORCID: 0000-0002-8195-6623.

2 „Pierwszym sytemem pisma była prawdopodobnie wczesna postać pisma klinowego, która pojawiła się w Mezopotamii około 3200 r. przed Chr.", S.M. Miller, R.V. Huber, Historia Biblii. Dzieje powstania i odczytania Pisma Świętego, (Przewodniki chrześcijańskie), tłum. E. Czerwińska, Warszawa 2005, S. 18; S.N. Kramer, Istorija prasideda Šumere. Trisdešimt devyni dalykai, pirma karta paminèti rašytinejje istorijoje, vert. A. Jurašius, Vilnius 2015, S. 14; G. Pettinato, I Sumeri, (Orizzonti della storia), Milano 1991, S. 33; S. Croatto, Uruk, in: Enciclopedia della Bibbia, a cura di A. Díez Macho, S. Bartina, vol. VI, Torino-Leumann 1971, S. 1067-1070; A. Paciorek, Wstęp ogólny do Pisma Świętego, (Academica 17), Tarnów 1999², S. 86; P. Weimar, Pismo, in: Praktyczny stownik biblijny, red. A. Grabner-Haider, tłum. T. Mieszkowski, P. Pachciarek, Warszawa 1995, S. 965-966; Z. Ziółkowski, Spotkania z Biblia, Poznań 1971², S. 36-37.
} 
Anwendung im alltäglichen Leben, wie Austrocknung der Sümpfe, Anlegen von Wasserkanälen, das Rad für die Töpferwerkstatt und für den Transport usw. Das alles beschleunigte die Entwicklung der Wirtschaft, welche wiederum das Niveau des Lebens verbesserte. Doch eine immer intensivere Produktion der Waren und der schnell sich entwickelnde Handel begannen auch die Alltäglichkeit der Menschen kompliziert zu machen. Es zeigte sich, dass ihr Gedächtnis nicht fähig ist, sich die immer weiter steigende Anzahl der Informationen zu merken. Die Erfindung der Schrift war die beste Lösung des entstandenen Problems ${ }^{3}$. Selbstverständlich war das noch nicht unser heutiges Alphabet-System ${ }^{4}$. Es wird vermutet, dass es etwa um 1500 v. Chr. von Phöniziern erfunden wurde ${ }^{5}$. Dennoch der Anfang wurde gemacht. Die Verbesserung des Schrifttums und seine Verbreitung war bloss eine Frage der Zeit. Und in Wirklichkeit entstanden im Laufe der Zeit neben den Warenkatalogen, Rechnungen und Listen der Schulden auch die anderen Gattungen des Schrifttums: Elegien, Liebesgedichte, philosophische Dialoge, Mythen usw. ${ }^{6}$. Einige Texte bekamen sogar einen sakralen Status und wurden während verschiedener religiöser Zeremonien verwendet ${ }^{7}$. Die Schrift wurde so eine eigene Form der menschlichen Unsterblichkeit: Wie Eltern in ihren Kindern weiterleben, so die Schriftsteller — in ihren Werken.

Heute können wir uns das Leben ohne Lesen und Schreiben nicht vorstellen. Der geschriebene Text ist einer der besten Freunde vieler Bewohner unseres Planeten ${ }^{8}$. So sind auch einige neue Formen des Schreibens und des Bewahrens der Information entstanden. Jedoch hat jede Sache in der Welt zwei Seiten - negative und positive. Das Phänomen der Schrift macht in diesem Falle keine Ausnahme. Das geschriebene Wort wird eher oder später gelesen, und lesen - bedeutet interpretieren. „So viele Leute, so viele Standpunkte“ — heisst die Maxime des Terentius (185-159). Man könnte auch sagen: So viele Leser, so viele Interpretationen. Und diese erschweren das Leben der Leser: Welche Interpretation ist dann die richtige? Dasselbe gilt auch für die Heilige Schrift. Die geschlossene Bibel verbindet,

${ }^{3}$ Vgl. S.N. Kramer, Istorija ..., S. 15; R. Stiller, Przed nami szedt Gilgamesz, in: Gilgamesz. Epos babiloński i asyryjski ze szczątków odczytany i uzupetniony także pieśniami szumerskimi przez Roberta Stillera, Kraków 20164, S. 111-153, hier: S. 112-115.

${ }^{4}$ Vgl. S.N. Kramer, Istorija ..., S. 15.

${ }^{5}$ Vgl. A. Angerstorfer, D. Harmening, M. Klöckener, Alphabet, in: Lexikon für Theologie und Kirche, hrsg. v. W. Kasper u. a., Bd. 1, Freiburg-Basel-Rom-Wien 1993³, S. 427-429.

${ }^{6}$ Vgl. S.N. Kramer, Istorija ..., S. 15-16; R. Stiller, Przed ..., S. 116.

${ }^{7}$ Es sei daran auch erinnert, dass das Schreiben an sich in der damaligen Kultur als besonderes Geschenk Gottes oder Götter galt; vgl. W.M. Schniedewind, How the Bible Became a Book. The Textualization of Ancient Israel, Cambridge 2005, S. 24.

${ }^{8}$ Trotzdem gibt es heute auch Analphabetismus in der Welt.

9 Vgl. A. Maceina, Daiktas ir žodis. Lietuviu kalbos filosofija, Vilnius 1998, S. 28; T. Maceinienè, Pradžioje buvo Žodis ...: pokalbiai su Antanu Maceina-Jasmantu apie poezija, Vilnius 2004, S. 105. 
die geöffnete - trennt $^{10}$. Aus diesem Grunde wurden in der Geschichte der biblischen Exegese, sowohl im Judentum, als auch im Christentum, verschiedene Methoden und Prinzipien der Interpretation der Bibel angewendet. Es entstand sogar eine selbstständige Disziplin — die biblische Hermeneutik ${ }^{11}$. Zu den Themen, mit denen sie sich beschäftigt, wurde schon viel Tinte verschrieben. Ein wichtiges Dokument dafür erschien - zum Beispiel — vor circa 25 Jahren. Es ist mit dem Titel Die Interpretation der Bibel in der Kirche bekannt und wurde von der Päpstlichen Bibelkommission im Jahre 1993 herausgegeben (weiterhin als IBK abgekürzt).

IBK stellt die unterschiedlichen Aspekte der damaligen Situation der Hermeneutik in Bezug auf die Interpretation der Heiligen Schrift dar. Seine Ergebnisse haben noch heute ihre Aktualität nicht verloren, wie für die wissenschaftliche Ebene so auch für die seelsorgliche. Diese letzte wird auch im IBK behandelt, und zwar unter der Nummer 3 des Punktes C des IV. Kapitels, welche vom Gebrauch der Bibel in der Seelsorge spricht: Die Priester, folgend der Empfehlung der Konstitution Dei Verbum (Nr. 24), müssten sich darum bemühen, dass die Heilige Schrift unter den Gläubigen möglichst oft gelesen wird. Sie sollten auch eine den Verständnismöglichkeiten der ihnen anvertrauten Christen angewendete Hermeneutig benutzen. Welche dann? IBK schlägt expressis verbis keine vor. Seelsorger müssten darin eigene Initiative zeigen, selbstverständlich die Richtlinien der katholischen Kirche zum Lesen der Bibel beobachtend. Eine solche den Gläubigen verständliche oder sagend mit den neutestamentlichen Worten in der Sprache der Unmündigen (Mt 11,25) ausgedrückte Hermeneutik wird in diesem Artikel angeboten. Das ist nämlich das hauptsächliche Anliegen dieses Textes. Darin versucht man die wichtigsten Grundsätze der katholischen Hermeneutik zum Lesen der Heiligen Schrift in der pastoral-katechetischen Sprache darzustellen. Das wird eigentlich in sechs Schritten erfolgen. Jeder Abschnitt wird ein gewisses hermeneutisches Prinzip besprechen und es mit einigen Beispielen illustrieren. Diese Publikation wird auch mit einem die ganze Arbeit bewertenden Nachwort abgeschlossen.

\section{Der erste Grundsatz: \\ Die Bibel wurde in keiner der heutigen Sprachen geschrieben}

Das ist eine Wahrheit, die alle oder fast alle kennen. Die Bibel wurde in den alten hebräischen, aramäischen und griechischen Sprachen geschrieben. Doch die theoretische Kenntnis mancher Wahrheiten bedeutet nicht unbedingt sie in der Praxis

\footnotetext{
${ }^{10}$ Vgl. B. Ferdek, Nasza Siostra - Córa i Matka Pana. Mariologia jako przestrzeń syntezy dogmatyki, (Biblioteka Diecezji Świdnickiej 13), Świdnica 2007, S. 28.

${ }^{11}$ Vgl. R. Rubinkiewicz, Historia egzegezy, in: Wstęp ogólny do Pisma Świętego, red. J. Szlaga, Poznań-Warszawa 1986, S. 276-287; J. Kudasiewicz, H. Witczyk, A. Zuberbier, Hermeneutyka biblijna, in: Stownik teologiczny, red. A. Zuberbier, Katowice 1998², S. 195-198.
} 
anzuwenden. Warum sollten dann die Gläubigen im Hinterkopf haben, dass die Bibel in keiner der heutigen Sprachen geschrieben wurde? Vor allem wegen folgender Argumente: 1) um Scheinschwierigkeiten zu vermeiden, 2) den Bereich des semantischen Feldes des Wortes auszubreiten und 3) die wahre Bedeutung des Textes zu verstehen.

1. Vermeidung der Scheinschwierigkeiten

Das Bewusstsein, dass die Bibel in keiner der heutigen Sprachen geschrieben wurde, sollte dem Leser helfen gewisse Missverständnisse, welche beim Lesen der Heiligen Schrift entstehen können, zu vermeiden. Zum Beispiel könnte eine erstlesende Person einige Schwierigkeiten beim folgenden Abschnitt des Briefes an die Galater bekomen:

Es gibt kein anderes Evangelium, es gibt nur einige Leute, die euch verwirren und die das Evangelium Christi verfälschen wollen. Jedoch, auch wenn wir selbst oder ein Engel vom Himmel euch ein anderes Evangelium verkündeten als das, das wir verkündet haben - er sei verflucht. Was ich gesagt habe, das sage ich noch einmal: Wer euch ein anderes Evangelium verkündet im Widerspruch zu dem, das wir verkündet haben - er sei verflucht $(1,6-9)^{12}$.

Der Brief an die Galater gehört zu den authentischen Schriften des heiligen Paulus. Doch kommt hier die Frage auf: Wie Paulus, der Völkerapostel und einer der grössten Heiligen aller Zeiten, sich getraut andersdenkende Menschen zu verdammen: Der Verkündiger eines anderen Evangeliums sollte, seiner Meinung nach, verflucht sein? Die Verteidiger des Paulus, die ihn rechtfertigen wollten, könnten zwei apologetische Argumente anführen: psychologisches und christologisches.

Das psychologische Argument. Als Paulus diesen Brief schrieb, war er wütend. Er kämpfte ja gegen die Verfälschung des Evangeliums Christi. Deshalb kam es aus seiner Feder so hervor und nicht anders. So eine Bemerkung ist ganz richtig. Dem Apostel war, in der Zeit des Schreibens dieses Briefes, nicht zum Scherzen zumute. Der christlichen Gemeinde in Galatien drohte tödliche Gefahr. Die wirkliche Doktrin der Rechtfertigung hatten einige Christen falsch verstanden und sie auf eine aggressive Art anderen verkündet. Man musste deshalb schnell und entschieden reagieren.

Das christologische Argument. Aus der Lektüre der kanonischen Evangelien ergibt sich, dass sogar Jesus Christus manchmal seine Gedanken extrem äusserte. Er verfluchte zum Beispiel den Feigenbaum (Mk 11,12-14.20-21), verglich eine

\footnotetext{
${ }^{12}$ Alle deutschsprachigen biblischen Zitate kommen aus der neuen revidierten Ausgabe der Einheitsübersetzung der Bibel (2016).
} 
heidnische Frau und ihre Tochter mit Hunden (Mk 7,24-30), antwortete ungehörig seiner Mutter (Joh 2,4) $)^{13}$ usw. Deshalb wenn Jesus, der ewige Sohn Gottes und vollkommenste Mensch sich ähnliche Äusserungen erlaubt hat, warum könnte dann nicht Paulus, der schwache und sündige Mensch das nicht auch machen?

Es gibt jedoch noch eine, und zwar philologische Möglichkeit der Lösung dieses Problems. Im griechischen Original liest man anstatt der Übersetzung er sei

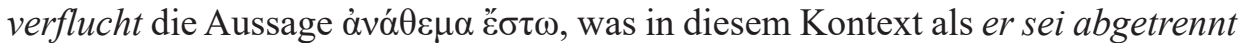
übersetzt werden könnte. Das griechische Wort $\alpha$ ó $\theta \varepsilon \mu \alpha$ drückt ja vor allem die Idee des religiösen Opfers aus, d. h. dessen, was aus dem täglichen Gebrauch ausgenommen ist ${ }^{14}$. Anders gesagt, in Übereinstimmung mit dem griechischen Text verflucht der heilige Paulus niemanden, sondern er ruft die Christen Galatiens auf, sich von den hinterlistigen und gefährlichen Häretikern fern zu halten und diese aus der Gemeinde auszuschliessen. In solcher Richtung übersetzt nämlich diese Stelle die sogenannte Paulinische Bibel (2008): Aber wenn wir selbst sogar oder ein Engel vom Himmel würde euch ein anderes Evangelium verkünden, wie dieses welches wir euch verkündet hatten, sei er aus der Gemeinschaft ausgeschlossen $(\mathrm{Ga} 1,8)^{15}$.

2. Verbreitung des semantischen Feldes

Wenn die Lektüre des Textes, wie oben gezeigt wurde, schon eine Interpretation ist, so gilt das noch mehr für die Übersetzung. Doch das ist nicht das grösste Problem, dem man begegnet, übersetzend aus einer in die andere Sprache. Die grösste Komplikation jeder Übertragung ist das Risiko der Verengung des semantischen Feldes des sprachlichen Zeichens. Hier ist eines von vielen möglichen Beispielen. Der Text des Dekaloges öffnet die Inaugurationsphrase: „Ich bin der HERR, dein Gott, der dich aus dem Land Ägypten geführt hat, aus dem Sklavenhaus“" (Ex 20,2). Das ist ein untergeordneter zusammengesetzter Satz, in dem der übergeordnete Teil mit dem untergeordneten Bereich mit Hilfe des Relativpronomens der verbunden ist. Der übergeordnete Satz beinhaltet die Selbstpräsentation Gottes: Ich bin der HERR, dein Gott. Und der untergeordnete Satz, der den Inhalt des Hauptsatzes entwickelt, beschreibt Gott als Befreier des auserwählten Volkes: Der dich aus dem Land Ägypten geführt hat, aus dem Sklavenhaus.

Der hebräische Text des Dekalogs beginnt auch mit einem zusammengesetzten Satz und seine Glieder werden auch mit dem Relativpronomen שֶׁ verbunden. Das letztere jedoch, im Unterschied zum Pronomen der, hat ein mehr ausge-

\footnotetext{
${ }^{13}$ Vgl. T. Schwartz, Auch Jesus hatte schlechte Laune. Überraschendes aus der Bibel, Freiburg-Basel-Wien 2017, S. 45-55.

${ }^{14}$ Vgl. H.W. Kuhn, Anathema, in: Dizionario Esegetico del Nuovo Testamento, a cura di H. Balz, G. Schneider, trad. R. Chiavarino, V. Gatti, E. Riboldi, vol. I, Brescia 1995, S. 213-214.

15 „Lecz gdybyśmy nawet my sami, albo gdyby anioł z nieba głosił wam ewangelię inną od tej, którą wam głosiliśmy, niech będzie wyłączony ze wspólnoty“ (Ga 1,8).
} 
bautes semantisches Feld. Deshalb könnte man die Anfangsphrase des Dekalogs folgendermassen übersetzen: Ich bin der Herr, dein Gott, weil ich dich aus dem Land Ägypten, aus dem Sklavenhaus, geführt habe. Übereinstimmend mit dieser Version, erinnert Gott der Herr in dem untergeordneten Satz nicht nur, was in der Vergangenheit für das auserwählte Volk getan wurde, sondern er zeigt auch, auf welche Weise er zum Gott der Israeliten und wie sie zu seinem Volk geworden waren. Welche Version von diesen ist besser? Beide sind in Ordnung, obgleich die zweite nur im Originaltext lesbar ist.

3. Wahre Bedeutung des Textes

Man muss auch bedenken, dass die Heilige Schrift in keiner der heutigen Sprachen geschrieben wurde, um die wahre Bedeutung des biblischen Textes zu verstehen. Jede Übersetzung der Bibel, wie schon erwähnt wurde, ist ebenfalls eine Interpretation. Das ist eine unvermeidliche Sache. Es gibt keine Übertragung der Heiligen Schrift ohne Sinndeutung. Doch nicht jede Interpretation ist richtig. Deshalb bestehen einige falsch übersetzte Fragmente, welche mit der originalen Bedeutung des biblischen Textes gar nichts zu tun haben. Eines von diesen befindet sich am Ende des Evangeliums nach Johannes. Im 21. Kapitel dieses Buches liest man über ein Gespräch zwischen dem auferstandenen Jesus Christus und Petrus. Dieser Dialog besteht aus drei Fragen und drei Antworten. Jesus Christus fragt und Petrus antwortet. Das Objekt dieses Gespräches ist die Liebe des Petrus zu Jesus Christus. Auf den ersten Blick läuft alles harmonisch und idyllisch. Besonders bei der ersten und zweiten Anfrage. Jesus fragt: Liebst du mich? (Joh 21,15b.16b.17b) und Petrus antwortet: Ich liebe dich! (Joh 21,15d.16d.17d). Nur bei der dritten Anfrage taucht eine Spannung auf. Im Text steht, dass Petrus traurig geworden ist (Joh 21,17c). Warum das geschah, ist dem Leser der Bibel in deutscher Sprache nicht klar. Petrus erhielt ja dieselbe Anfrage wie das erste und zweite Mal. Diese Traurigkeit des Petrus ist ein Zeichen, welches einige Schwierigkeiten dieser Perikope bezeichnet. Um das zu verstehen, worum es hier geht, muss man sich daran erinnern, dass die Bibel in keiner der modernen Sprachen geschrieben wurde. Deutsch gehört zweifellos dazu. Die ersten deutschen Übersetzungen der Heiligen Schrift entstanden erst im VIII. Jahrhundert ${ }^{16}$. Der Inhalt dieses Textes, mit dem man sich jetzt beschäftigt, wurde aramäisch ausgesprochen und später griechisch aufgeschrieben. In der Zeit Jesu sprach man ja im Gelobten Land normalerweise aramäisch. Selbstverständlich beherrschten einige Bewohner auch die griechische Sprache, weil diese seit der Eroberung Palästinas durch Alexander den Grossen (356-323) ziemlich verbreitet war, be-

${ }^{16}$ Vgl. O.B. Knoch, K. Scholtissek, Bibel. VIII. Bibelübersetzungen. 3. Mittelalterliche, neuzeitliche $u$. moderne europäische Übersetzungen, in: Lexikon für Theologie und Kirche, hrsg. v. W. Kasper u. a., Bd. II, Freiburg-Basel-Rom-Wien 1994³, S. 388-398, hier: S. 388. 
sonders in den Städten. Deshalb war es kein Wunder, dass für das Aufschreiben des Neuen Testaments die griechische Sprache benutzt wurde. Damals war sie im römischen Imperium ungefähr so verbreitet wie heute Englisch. Und die griechische Variante des Gesprächs zwischen Jesus und Petrus hat zum Unterschied zur deutschen Übersetzung eine Eigenschaft: Sie beinhaltet zwei verschiedene Verben. In der Frage Jesu benutzt man das Verb àyatá $\omega$ und in der Antwort des Petrus steht das Wort $\varphi \imath \lambda \varepsilon ́ \omega$. Das gilt für die ersten zwei Fragen Jesu und auch für die ersten zwei Antworten Petri. Jesus fragt $\dot{\alpha} \gamma \alpha \pi \tilde{\alpha} \varsigma \mu \varepsilon$, Petrus antwortet $\varphi \imath \lambda \tilde{\omega}$ $\sigma \varepsilon$. Das wird zweimal wiederholt und nur beim dritten Mal kam eine Änderung. Jesus benutzte nicht das Verb $\alpha \gamma \alpha \pi \alpha ́ \omega$, sondern $\varphi \imath \lambda \varepsilon ́ \omega$. Die Antwort Petri blieb dieselbe. Er benutzte nur das Wort $\varphi 1 \lambda \varepsilon ́ \omega$. Die deutsche Übersetzung, wie schon gesagt, macht keinen Unterschied zwischen $\alpha \gamma \alpha \pi \alpha ́ \omega$ und $\varphi \imath \lambda \dot{\varepsilon} \omega$. Sie überträgt diese zwei verschiedenen Worte mit dem gleichen Wort lieben. Und das ist ein ziemlich grosses Problem. Die wirkliche Bedeutung des Textes bleibt verborgen. Normalerweise kommentiert man dieses Gespräch folgendermassen: Der heilige Petrus hatte dreimal Jesus verleugnet, deshalb sollte er dreimal seine Liebe zu ihm bekennen ${ }^{17}$. Natürlich könnte man diesen Text auch so interpretieren. In solchem Falle verweilt man aber an der Oberfläche dieses Gespräches. Die tiefere Bedeutung bleibt unentdeckt. Und diese ist sehr wichtig, besonders für die spirituelle Ebene des christlichen Lebens. Für eine bessere Erklärung des Textes könnte man ein Beispiel anführen. Man stelle sich ein Gespräch zwischen dem Fussballtrainer und einem Fussballspieler vor. Der Trainer fragt: Kannst du drei Tore im Spiel schiessen? Der Spieler antwortet: Normalerweise schiesse ich nur ein Tor. Bei der zweiten Frage und Antwort herrscht dieselbe Situation. Der Trainer fragt um drei Tore und der Spieler erklärt sich bereit nur ein einziges Tor zu schiessen. Beim dritten Mal kommt etwas Neues. Der Trainer fragt nicht mehr um drei Tore, aber nur um ein Tor. Und der Spieler sagt zu: Das kann ich! Doch der Trainer macht ihm ein Angebot: Komm zu meinem Training und ich lehre dich sogar drei Tore zu schiessen.

Etwas Ähnliches geschah während des Gesprächs zwischen Jesus und Petrus. Wie schon gesagt wurde, im griechischen Text sind zwei verschiedene Verben: $\grave{\alpha} \gamma \alpha \pi \alpha ́ \omega$ und $\varphi \imath \lambda \dot{\varepsilon} \omega$. Diese Verben bedeuten die Liebe, aber drücken verschiedene

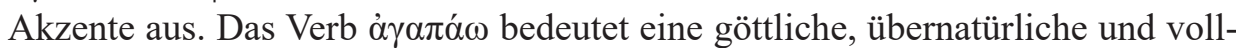
kommene Liebe, welche sogar die Feinde umfasst und ihnen Gutes wünscht und tut. Anders ist es mit dem Wort $\varphi \imath \lambda \dot{\varepsilon} \omega$. Dieses Verb bezeichnet auch eine Liebe, aber in diesem Kontext nur die menschliche und unvollkommene Liebe, welche für die Anderen Gutes will, doch nur dann, wenn diese freundlich sind. Mit an-

${ }^{17}$ „The threefold question addressed to Peter alone corresponds to the threefold denial. Jesus gives Peter charge over his flock“, The Revised Standard Version of the Bible: Catholic Edition, 1965, [online] https://www.biblegateway.com/passage/?search=joh+21\&version=RSVCE [16.02.2019]. 
deren Worten, Jesus fragte bei Petrus nach einer vollkommenen Liebe (drei Tore) und Petrus bekannte nur seine unvollkommene Liebe (ein Tor). Bei der zweiten Anfrage herrschte dieselbe Situation: Jesus fragte nach $\dot{\alpha} \gamma \alpha \pi \dot{\alpha} \omega$ (drei Tore) und Petrus antwortete nur mit $\varphi \imath \lambda \varepsilon ́ \omega$ (ein Tor). Die entscheidende Änderung entstand

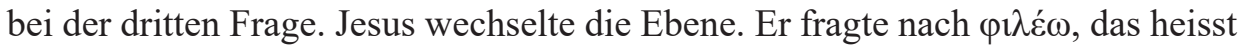
nach menschlicher Liebe (ein Tor) und Petrus war dazu bereit. So etwas war ihm möglich. Ungeachtet dessen, wie man im Text liest, wurde er traurig. Die Ursache dieser Traurigkeit war die Herabsetzung der Ebene der Liebe: Anstelle der vollkommenen Liebe eine unvollkommene Liebe. Normalerweise sollte die Reaktion des Petrus eine ganz andere sein. Er sollte sich darüber freuen. Jesus Christus verlangt einerseits eine vollkommene Liebe, aber andererseits ist er zufrieden mit dem, was der Mensch ihm hic et nunc geben kann. Und das ist sehr tröstlich für das geistliche Leben der Christen. Gott der Herr akzeptiert was jeder Ihm heute anbieten kann. Wenn man leidet, erwartet er keine Fröhlichkeit, und wenn man zufrieden ist, zwingt er niemanden ernst zu sein. Aber dies alles kann man nur aus dem griechischen Text herausfinden. In der deutschen und leider in vielen anderen Übersetzungen gibt es diese Möglichkeit nicht. Verantwortlich dafür ist eine unvollkommene Übertragung, welche zwei verschiedene griechische Worte ( $\alpha \gamma \alpha \pi \alpha \dot{\alpha} \omega, \varphi \imath \lambda \dot{\varepsilon} \omega)$ mit einem und demselben Wort (lieben) übersetzt. Ein Vorschlag dafür wäre folgender: Man könnte das Verb $\varphi \imath \lambda \varepsilon \dot{\varepsilon} \omega$ mit der Aussage lieb haben übertragen. In diesem Fall würde der heilige Petrus auf die Frage Jesu nicht ich liebe dich, aber ich habe dich lieb antworten. Und ich habe dich lieb würde eine niedrigere Ebene der Liebe bezeichnen. Jesus fragte nach der vollkommenen Liebe und Petrus bekannte nur diese unvollkommene. Aber weil er Jesus nachgefolgt war (Joh 21,19c), hatte er auch diese höhere Ebene der Liebe erreicht. Ein Zeichen dafür ist sein Tod für Jesus am Kreuz mit dem Kopf nach unten (Joh 21,18-19a) $)^{18}$.

\section{Der zweite Grundsatz:}

\section{Die Bibel wurde nicht von europäischen Autoren geschrieben}

Diese Tatsache kennen auch alle: Die Heilige Schrift wurde von Autoren semitischer Herkunft geschrieben. Eine Ausnahme bildet wahrscheinlich nur der heilige Lukas, Verfasser des dritten kanonischen Evangeliums und der Apostelgeschich-

\footnotetext{
${ }^{18}$ Vgl. D. Dikevičius, Dèl $\varphi$ $\imath \varepsilon \dot{\varepsilon} \omega$ vertimo, in: Duosiu jums ganytojų pagal savo širdį. Minint Vilniaus šv. Juozapo kunigu seminarijos atkūrimo dvidešimtmetį, red. D. Dikevičius, I. Gudauskienè, (Bibliotheca Sancti Josephi 4), Vilnius 2014, S. 69-74, hier: S. 69-72; D. Dzikiewicz, Die revidierte Ausgabe der Einheitsübersetzung. Einige Beispiele verpasster Korrekturmöglichkeiten, „Studia Theologica Grodnensia“ 12 (2018), S. 89-102, hier: S. 98-99.
} 
te, welcher griechische Wurzeln hatte. Doch wurde er auch von der semitischen Kultur beeinflusst. Dieser Grundsatz unterstreicht jedoch nicht die Nationalität der biblischen Schriftsteller, aber ihre kulturelle Identität, welche zum Ausdruck bringt: 1) die Einzigartigkeit des Denkens der Bibelautoren und 2) die Einzigartigkeit der literarischen Formen der Heiligen Schrift.

\section{Einzigartigkeit des Denkens der Bibelautoren}

Die Bibel als Buch ist nicht vom Himmel gefallen. Es ist ein historisches Werk, aufgeschrieben durch historische Verfasser und an die Menschen gerichtet, die in einer bestimmten Zeit der Geschichte lebten. Deshalb, um die Heilige Schrift zu verstehen, so steht in Dei Verbum, „muss man [...] auf die vorgegebenen umweltbedingten Denk-, Sprach- und Erzählformen achten, die zur Zeit des Verfassers herrschten, wie auf die Formen, die damals im menschlichen Alltagsverkehr üblich waren" (Nr. 12). Dafür ein einfaches Beispiel. Die Menschen Europas als Erben der griechisch-römischen Zivilisation tröstend einen jungen Menschen sagen gewöhnlich: Sei nicht verzweifelt! Alles in deinem Leben liegt noch vor dir! Laut dieser Logik liegt die Zukunft vor jedem Menschen. Die Kommunisten, wie man weiss, versprachen eine glückliche Zukunft. Aus diesem Grunde stellten sie normalerweise verschiedene Denkmäler von Lenin auf, der einer der Gründer des Kommunismus war, mit einer ausgestreckten Hand nach vorn. Das sollte ein Zeichen für die glücklichen zukünftigen Zeiten sein. Der biblische Mensch denkt in diesem Falle anders. Nach ihm liegt die Vergangenheit vor ihm, und die Zukunft - hinter ihm. Aber warum? Vor allem, weil die Vergangenheit bekannt ist, deshalb könnte man sagen sie ist „sichtbar“, und die Zukunft - ist unbekannt, deshalb „unsichtbar“, aus diesem Grunde liegt sie hinter dem Menschen, wo keine Augen sind. Der König David, als er Gott für die Sünden der Vergangenheit (2 Sam 11) um Barmherzigkeit bat, flehte: „Gott, sei mir gnädig [...]! Wasch meine Schuld von mir ab und mach mich rein von meiner Sünde! Denn ich erkenne meine bösen Taten, meine Sünde steht mir immer vor Augen“ (Ps 51,3-5). Die begangenen Sünden stehen vor ihm: vor Augen. Die Vergangenheit ist dann vorn. Solche und ähnliche semitische Art und Weise des Denkens der biblischen Autoren befindet sich überall in der Heiligen Schrift: Die Eltern und Verwandten hassen (Mt 10,37), die andere Wange anbieten (Mt 5,39), das zweite Hemd abgeben (Mt 5,40) etc. Nur das Verständis, dass es hier um Semitismen geht, kann diese aufgezählten, sowie andere Stellen in der Bibel verständlich machen.

2. Einzigartigkeit der literarischen Formen der Heiligen Schrift

Die biblischen Autoren schrieben in menschlicher Art - als wahre Schreibkünstler, deshalb wurde die Offenbarung Gottes nicht nur aufgeschrieben, sondern auch leibhaftig. In der Theologie wird dieser Prozess der Verwurzelung des Wortes Gottes in der menschlichen Geschichte Inkulturation genannt. In den 
biblischen Texten wird diese durch verschiedene literarische Mittel ausgedrückt. Deshalb schreibt man dazu in Dei Verbum das folgende: „um die Aussageabsicht der Hagiografen zu ermitteln, muss man neben anderem auf die literarischen Gattungen achten“ (Nr. 12). Zum besseren Verständnis sei hier ein Beispiel angeführt. Wie man weiss, war das Leben Abrahams mit verschiedenen Prüfungen ausgefüllt. Die jüdische Tradition führt insgesamt zehn solcher Fälle an. Die grösste davon war sicher die Opferung Isaaks, von der man im Abschnitt 22 des Buches Genesis liest. Ziemlich oft wird dieses Fragment als bester Beweis für den Glauben Abrahams zitiert. Das wird auch mit einem ähnlichen Kommentar begleitet: Seht mal, wie gross der Glaube Abrahams war! Gott befahl ihm den Isaak zu opfern und er hat ihn nicht einmal gefragt: Warum? Und in der Tat, der Hauptpatriarch Israels stellt Gott keine Fragen. Doch so ein Kommentieren dieses Ereignisses ist gefährlich und falsch, weil auf solche Weise Abraham als Übermensch dargestellt wird, der begeistert, aber nicht engagiert seinem Beispiel zu folgen und, weil es für Abraham nicht leicht war den Willen Gottes zu hören und ihn auszuführen. Woher weiss man das? Das geht aus dem biblischen Text selbst hervor:

Nach diesen Ereignissen stellte Gott Abraham auf die Probe. Er sprach zu ihm: Abraham! Er sagte: Hier bin ich. Er sprach: Nimm deinen Sohn, deinen einzigen, den du liebst, Isaak, geh in das Land Morija und bring ihn dort auf einem der Berge, den ich dir nenne, als Brandopfer dar! Frühmorgens stand Abraham auf, sattelte seinen Esel, nahm zwei seiner Jungknechte mit sich und seinen Sohn Isaak, spaltete Holz zum Brandopfer und machte sich auf den Weg zu dem Ort, den ihm Gott genannt hatte (Gen 22,1-3).

Auf den ersten Blick verwundert wirklich die stoische Ruhe Abrahams. Vielleicht disponierte er eine Information, die eigentlich nur dem Leser zugänglich ist und wusste, dass es nur eine Probe war? Doch Abraham hatte dieses Wissen nicht. Dass es nur um eine Probe ging, weiss nur der Leser dieses Abschnittes. Worum geht es dann hierbei? Die Antwort steckt zwischen den Versen. Die gründliche Analyse des Textes, und besonders des dritten Verses, zeigt uns ein so ganz anderes Bild Abrahams. Es würde ausreichen auf die biblische Reihenfolge des Handelns Abrahams zu schauen:

\begin{tabular}{l}
\hline 1. stand auf \\
\hline 2. sattelte seinen Esel \\
\hline 3. nahm die Jungknechte und seinen Sohn \\
\hline 4. spaltete Holz \\
\hline 5. machte sich auf den Weg
\end{tabular}


Doch die logische Reihenfolge der Tätigkeit Abrahams müsste eine andere sein:

\begin{tabular}{l}
\hline 1. stand auf (1) \\
\hline 2. spaltete Holz (4) \\
\hline 3. sattelte seinen Esel (2) \\
\hline 4. nahm die Jungknechte und seinen Sohn (3) \\
\hline 5. machte sich auf den Weg (5) \\
\hline
\end{tabular}

Man sieht also, dass die biblische und die logische Reihenfolge der Handlung Abrahams sich unterscheiden. Abraham stand auf (1), bereitete den Esel für den Weg (2), rief die Knechte und den Sohn (3), welche dastehend zuschauten wie er das Holz für das Opfer vorbereitete (4). Erst dann machte er sich auf den Weg (5). Normalerweise sollte Abraham zuerst, aus dem Schlaf erwachen (1/1), das Holz vorbereiten (2/4), dann den Esel satteln (3/2), die Knechte und den Sohn rufen (4/3) und nur dann aufbrechen (5/5). Dies alles würde bedeuten, dass Abraham schockiert war und die aufgeführten Tätigkeiten tief erlebte. Der Wille Gottes war für ihn eine grosse Erschütterung und eine kolossale Überraschung. Er vollbrachte ihn, doch es kostete ihn viel Kraft: Den Patriarchen „fieberte“. Die narrative Reihenfolge der Handlung Abrahams stand gegen den gesunden Verstand. Dieses Beispiel zeigt ein sehr wichtiges Merkmal der biblischen Hagiografie, nämlich das Geheimnisvolle der Bibel. Die biblische Literatur, die grundsätzlich ein Produkt der semitischen Kultur ist, im Gegensatz zur griechisch-römischen Literatur, informiert den Leser nicht immer über alles in öffentlicher Weise. Über viele Dinge muss der Lektor selbst zwischen den Versen lesen. Das erschwert sicher die Lektüre, aber gleichzeitig kennzeichnet es das Vertrauen gegenüber dem Leser und das Vertrauen auf seine Intelligenz: Er wird den Text früher oder später verstehen ${ }^{19}$.

\section{Der dritte Grundsatz: \\ Die heutigen Menschen sind nicht die ersten Leser der Bibel}

Das ist auch normalerweise eine allgemein bekannte Wahrheit. Sie geht aus dem Alter der Bibel hervor. Die Heilige Schrift wurde ja in längst vergangenen Zeiten geschrieben. Die ältesten ihrer Texte stammen ungefähr aus dem XII. Jahrhundert vor Christus (z.B. Ri 5$)^{20}$ und die jüngsten datiert man ca. um das I.-II. Jahrhun-

19 Vgl. E. Auerbach, Mimesis. Tikrovés vaizdavimas Vakarų pasaulio literatūroje, vert. A. Gailius, Vilnius 2003, S. 7-30.

${ }^{20}$ Vgl. J. Huesman, Judges, in: A New Catholic Commentary on Holy Scripture, ed. by R.C. Fuller, L. Johnston, C. Kearns, Nashville-Camden-New York 1984³, S. 294-302, hier: S. 297. 
dert nach Christus (z.B. Joh) ${ }^{21}$. Ein anderes Zeichen, welches darauf hinweist, dass die heutigen Menschen nicht die ersten Leser der Bibel sind, kann man darin sehen, dass die Heilige Schrift das am meisten gelesene Buch der Menschheit war und ist. Ob es mit Homer, Goethe oder Schiller verglichen wird, die Bibel schlägt sie alle um Längen und sogar ungeachtet der verschiedenen Verfolgungen, welche dieses Buch im Laufe der Zeit erfuhr. Die Statistik ist vielsagend: Die Bibel wurde als Ganzes bis jetzt ungefähr in 450 Sprachen übersetzt und einige ihrer einzelnen Teile liegen bereits in ca. 2400 Überetzungen vor. Jährlich werden etwa 700 Millionen der Heiligen Schrift gedruck ${ }^{22}$. Warum ist es aber wichtig sich daran zu erinnern, dass wir nicht die ersten Leser der Bibel sind? Eigentlich aus zwei Gründen: in Bezug auf 1) die sogenannte Regel des Glaubens und 2) die praktische Handhabung.

1. Regel des Glaubens Martin Luther (1483-1546), der Vater der Reformation, verkündend den Grundsatz Sola Scriptura, lehnte die Tradition ab und veröffentlichte die Autonomie und die Selbstgenügsamkeit der Heiligen Schrift. So bestand die Losung der Reformatoren: Quod non est biblicum, non est theologicum — Was nicht biblisch ist, ist auch nicht theologisch. Mit anderen Worten, nur dies kann Gegenstand des Glaubens sein, was in der Bibel geschrieben steht und was sich nicht in der Schrift befindet, kann auch nicht im Credo der Kirche ausgedrückt werden ${ }^{23}$. Diese Ansicht hat in grundsätzlicher Weise das Magisterium der Kirche bestritten, weil a) am Anfang das Wort und nicht die Schrift war und, b) weil es ohne die Tradition überhaupt keine Heilige Schrift gäbe.

Was bedeutet dann eigentlich, dass am Anfang das Wort und nicht die Schrift war? Auf diese Frage könnte man mit einem Beispiel antworten. Wann Abraham lebte, weiss man nicht genau. Dazu gibt es verschiedene Hypothesen. Aber die klassische sagt, dass sein Leben zwischen dem XX. und XVIII. Jahrhundert vor Christus zu platzieren ist. Er wurde von Gott zum Patriarchen des auserwählten Volkes berufen (Gen 12,1-4). Gott sprach sein Wort und Abraham hörte zu. Und nur später wurde dieses Ereignis aufgeschrieben. Am Anfang stand das Wort und nicht die Schrift. Abraham wurde ungefähr zwischen dem XX. und XVIII. Jahrhundert berufen und der Bericht über dieses Geschehen wurde erst zwischen dem X. und VI. Jahrhundert aufgeschrieben. Und dieser Bericht sollte auch mit der

${ }^{21}$ Vgl. R.E. Brown, An Introduction to the New Testament, (The Anchor Bible Reference Library), New York-London-Toronto-Sydney-Auckland 1997, S. 334; D.R. Russell, St John, in: A New Catholic Commentary on Holy Scripture, ed. by R.C. Fuller, L. Johnston, C. Kearns, Nashville-Camden-New York 1984³, S. 1022-1074, hier: S. 1030-1031.

${ }^{22}$ Vgl. H. Jaeger, M. Wäsch, Das Buch der Superlative, in: Die Bibel. Daten. Fakten. Wissenswertes, (Kurzgefasst), hrsg. v. H. Jaeger, M. Wäsch, Dillenburg 2013², S. 7-8, hier: S. 7.

${ }^{23}$ Vgl. H. Vorgrimler, Naujasis teologijos žodynas, vert. G. Žukas, Kaunas 2003, S. 211. 
mündlichen Tradition, welche von der Berufung Abrahams jahrhundertelang erzählte, übereinstimmen ${ }^{24}$.

Und was bedeutet, dass es ohne die Tradition überhaupt keine Heilige Schrift gäbe? Wieder könnte man das mit einem Beispiel illustrieren. Das Neue Testament besteht aus 27 Büchern. In der jetzigen Zeit kann man zu dieser Sammlung kein neues Buch zufügen und aus ihr keines herausnehmen. Doch es war nicht immer so. Es gab auch Zeiten, in denen einige christliche Gemeinden lasen, was heute mit dem Namen Apokryphen bekannt ist. Zum Beispiel der Brief von Barnabas, der Hirte von Hermes und Briefe von Clemens von Rom. Diese hier genannten Schriften wurden auch als Gottes Worte betrachtet und in der Liturgie gelesen. Nur die Kirche bestimmte später was als Wort Gottes gilt und was nicht ${ }^{25}$. Deshalb gibt es nämlich keine Bibel ohne Tradition. Anders gesagt, der dritte Grundsatz, paraphrasierend die oben erwähnte Devise der Protestanten, heisst: Quod non est theologicum, non est biblicum - Was nicht theologisch auch nicht biblisch ist. Das würde bedeuten, was nicht übereinstimmt mit der Regel des Glaubens, auch keine Heilige Schrift ist. Die tatsächliche katholische Lektüre und Exegese der Bibel kann nicht in Opposition zur Dogmatik stehen ${ }^{26}$.

\section{Die praktische Handhabung}

Man muss im Kopf haben, dass die heutigen Menschen nicht die ersten Leser der Bibel sind in Bezug auf die praktische Handhabung. Die hermeneutische Diskussion im 20. Jahrhundert, die durch Forschung von F.D.E. Schleiermacher (1768-1834) begonnen und dank der Bemühungen von M. Heidegger (18891976) und H.G. Gadamer (1900-2002) weiterentwickelt wurde, zeigte auf, dass für jede Interpretation des Textes das sogenannte vorhergehende Verstehen charakteristisch ist ${ }^{27}$. Die Interpretation der Heiligen Schrift ist keine Ausnahme. Es gibt in der Erklärung der Bibel, wie sonst auch im Leben, keine Null-Exegese ${ }^{28}$. Die Heilige Schrift in ihrer Ganzheit und in einzelnen Versen besitzt eine über

${ }^{24}$ „Nie dlatego wierzymy w Chrystusa, że mówi nam o Nim Pismo Święte, ale dlatego Biblia jest dla nas Pismem Świętym, że wynika to z naszej wiary w Chrystusa, Syna Bożego“, J. Salij, Pytania nieobojętne, Kraków 1986, S. 55.

${ }^{25}$ Vgl. H.Y. Gamble, Canon. New Testament, in: The Anchor Yale Bible Dictionary, ed. by D.N. Freedman, vol. I, New Haven-London 2008, S. 852-861.

${ }^{26}$ „Jakaś epoka nie może wykraczać poza to, co przez Ducha Świętego zostało sformułowane w dogmacie i podane jako klucz lektury Pisma świętego", Międzynarodowa Komisja Teologiczna, Interpretacja dogmatów, in: Od wiary do teologii. Dokumenty Międzynarodowej Komisji Teologicznej 1969-1996, red. J. Królikowski, Tarnów 2000, S. 273-302, hier: S. 291.

27 Vgl. V. Mannucci, Biblia come Parola di Dio. Introduzione generale alla Sacra Scrittura, (Strumenti 17), Brescia 1989¹0, S. 290-294; H. Vorgrimler, Naujasis ..., S. 211.

28 „Gdy obecnie podejmujemy problem prawdy [...] nigdy nie zaczynamy od zera. [...] By przystąpić do interpretacji, należy więc zbliżyć się również do świadectw historii, które tradycja już nam przekazała [...]“, Międzynarodowa Komisja Teologiczna, Interpretacja ..., S. 273. 
tausendjährige Geschichte der Interpretation. Das ist ein sehr gewaltiger Schatz, den ein Bibelkundiger nutzen muss (Mt 13,52). Der wirkliche Exeget ist auch ein Patrologe. Das könnte man mit folgendem Beispiel illustrieren. Im Evangelium nach Johannes liest man: „Als sie aber zu Jesus kamen und sahen, dass er schon tot war, zerschlugen sie ihm die Beine nicht, sondern einer der Soldaten stiess mit der Lanze in seine Seite und sogleich floss Blut und Wasser heraus" (19,33-34). Die Worte sogleich floss Blut und Wasser heraus wurden in der Geschichte der Exegese verschiedenartig interpretiert. Normalerweise sieht man hier die zwei wichtigsten Sakramente der Kirche: Taufe und Eucharistie ${ }^{29}$. Aber nicht nur. Deshalb ist einer der schönsten Kommentare die Erklärung des heiligen Augustinus (354-430), der diesen Abschnitt interpretiert anknüpfend an Gen 2,21-22: Wie aus der Rippe des schlafenden Adam das erste Weib - Eva geschaffen wurde, so wurde aus der durchstossenen Seite des im Tode schlafenden am Holze des Kreuzes zweiten Adam das zweite Weib - die Kirche geschaffen ${ }^{30}$. Solche treffende Interpretation konnten nur die Kirchenväter vorschlagen. Ein katholischer Leser und Exeget der Bibel kann und muss sie nutzen. Zum zweiten Mal muss man nicht ein Fahrrad erfinden. Der katholische Exeget sollte nicht nur ein Dogmatiker, sondern auch ein Patrolog sein.

\section{Der vierte Grundsatz: \\ Die heutigen Menschen werden nicht die letzten Leser der Bibel sein}

Das Lesen der Heiligen Schrift und ihre Exegese werden nicht ewig dauern. Diese sind auf eine bestimmte Zeit begrenzt. Sie werden bis zur sogenannten Parusie bestehen. Sie wird der letzte Termin aller Forschungen der Menschheit sein. Das theologische Studium wird in diesem Falle keine Ausnahme machen (1 Kor 13,8b). Die Parusie ist sicher, nur ihr Zeitpunkt ist unsicher (Mk 13,32), deshalb muss man sich beeilen (1 Kor 7,29b). Jedoch geht es im vierten Grundsatz nicht nur darum. Den entscheidenden Sinn dieser Regel bildet die Ermunterung zur ständigen Offenheit für das novum der modernen Hermeneutik und der Exegese. Die Geschichte der Interpretation der Heiligen Schrift zeugt davon, dass die Kirche nicht immer wohlwollend eingestellt war gegenüber exegetischen Innovationen. Als Beispiel könnte man die sehr kontroverse Geschichte „der Kanonisation“ der sogenannten geschichtlich-kritischen Methode anführen. Diese Methode war in den akademischen protestantischen Milieus und besonders bei den liberalen Protestanten, sowie in den nichtkirchlichen Kreisen schon von der Zeit der Aufklärung bekannt

\footnotetext{
${ }^{29}$ Vgl. R. Fabris, Giovanni, (Commenti biblici), Roma 1992, S. 986-988.

${ }^{30} \mathrm{Vgl}$. Augustin, Lectures or Tractates on the Gospel According to the St. John, transl. and ed. by J. Gibb, J. Innes, Grand Rapids 1983, CXX, 2, S. 647.
} 
und praktiziert. Hingegen in der römisch-katholischen Kirche wurde diese Methode endgültig approbiert erst am 18. November 1965, während der Schlussession des II. Vatikanischen Konzils. Es ging jedoch in diesem Prozess nicht ohne die Suspension des Lehrstuhles der einzelnen Professoren und das Verbot oder die Verbrennung ihrer Bücher. Es wurde auch die Autorität einiger päpstlichen Enzykliken in Frage gestellt. Beispielsweise könnte man sich hier an den Fall des Oratorianers Richard Simon (1638-1712) erinnern. Er, wie man weiss, gab im Jahr 1678 ein Buch über die kritische Geschichte des Alten Testamentes (Histoire critique du Vieux Testament) heraus. Diese Publikation wurde nicht nur verboten, sondern auch verbrannt. Doch einige Stücke von ihnen überlebten und erreichten unsere Tage. Heute gilt dieses Buch als die erste katholische systematische Einführung in die Bibel und sein Autor ist unter den Bibelwissenschaftlern hochgeschätzt. Damals verlor er jedoch seinen Lehrstuhl und wurde aus dem Oratorianerorden entlassen. Etwas Ähnliches geschah mit der berühmten Enzyklika Divino Afflante Spiritu von Papst Pius XII., welche am 30. September 1943 erschien. Einer der wichtigsten ihrer Leitmotive besteht darin, dass sie beim Studium der Heiligen Schrift die Beachtung der literarischen Gattungen vorschlägt. In der heutigen Exegese ist das selbstverständlich. Ein Autor, welcher die literarischen Gattungen nicht beachtete, würde als ein biblischer Analphabet angesehen. Damals war es nicht so. Die neu erschienene Enzyklika bekam scharfe Kritik, besonders aus dem Kreis der amerikanischen kirchlichen Hierarchie. Heute hat sich die Situation geändert. Die offizielle Kirche ist für verschiedene exegetische Neuigkeiten offener geworden. Zum Beispiel wurde die kirchliche Anerkennung der sogenannten Methoden der literarischen Analyse der Bibel ziemlich schnell und fast schmerzlos durchgeführt. Das geschah im Jahre 1993: Die päpstliche biblische Kommission verkündete das Dokument IBK, welches viele und reiche Früchte trägt. Dafür ein einfaches Beispiel. Es gibt zwei Vaterunser Texte: Einer bei Matthäus (6,9-13) und einer bei Lukas $(11,2-4)$. Unter den Wissenschaftlern diskutiert man über ihre Herkunft und ihr Alter. Normalerweise sagt man auch, dass dieses Gebet aus zwei Teilen besteht. Der erste Teil spricht über die Beziehung zwischen Gott und Mensch und der zweite beschreibt das Verhältnis zwischen den Menschen ${ }^{31}$. Es gibt aber noch einen Brennpunkt. Die Wissenschaftler ,zerbrechen sich den Kopf“ zählend die Bitten dieses Gebetes im Evangelium nach Matthäus. Die einen sagen es seien sieben und die anderen nur sechs. Syntaktisch gesehen sind beide Möglichkeiten richtig. Deshalb kann man solche biblischen Kommentare finden,

${ }^{31}$ Vgl. R.T. France, The Gospel of Matthew, (The New International Commentary on the New Testament), Grand Rapids-Cambridge 2007, S. 241-244; D.J. Harrington, The Gospel of Matthew, (Sacra Pagina 1), Collegeville 1991, S. 97-99; J. Homerski, Ewangelia wedlug św. Mateusza. Wstęp, przektad z oryginalu, komentarz, (Pismo Święte Nowego Testamentu: III/1), Poznań-Warszawa 1979, S. 146. 
welche die erste Hypothese unterstützen und auch diese, die zur zweiten These neigen $^{32}$. Aber man sollte bei dieser Diskussion die Ergebnisse der rhetorischen Analyse beachten, welche im Dokument IBK anerkannt und als nützliche im Bibelstudium vorgeschlagen wurden. Die rhetorische Analyse, vergleichend mit der historisch-kritischen Methode, beschäftigt sich mit dem Text als Ganzes und beobachtet was sich in ihm wiederholt. Besonders wichtig ist diese letzte Sache. Die Wiederholungen spielen auch eine wichtige Rolle im Gebet des Herrn nach Matthäus. Es wurde in diesem Evangelium nach dem Modell der sogenannten Menora verfasst. Diese ist ein siebenarmiger Leuchter. Er stammt ungefähr aus dem XIII. Jahrhundert vor Christus und ist heute zum Hauptsymbol des Judentums geworden. Die Menora besteht eigentlich aus zwei Teilen: Aus dem Unterbau und sieben Leuchterarmen. Etwas Ähnliches repräsentiert das Vaterunser bei Matthäus. Es hat auch einen „Unterbau“ und sieben „Leuchter“. Der Unterbau besteht aus den Worten Unser Vater im Himmel. Und die Leuchter sind die Bitten. Diese letzten sind nach dem Prinzip des konzentrischen Parallelismus (A B C D C B A) aufgebaut, und zwar: Das Thema der ersten Bitten (die Heiligkeit des Namens Gottes) wiederholt sich in der siebten Bitte (Rettung aus dem Bösen); die zweite (das Reich Gottes) in der sechsten (die Versuchung) und die dritte (der Wille Gottes) in der fünften (Vergebung der Sünden). Selbständig bleibt nur die vierte Bitte um tägliches Brot. Daraus kann man die Schlussfolgerung ziehen, dass das Vaterunser im Evangelium nach Matthäus nicht aus sechs, sondern aus sieben Bitten besteht. Dieses Ergebnis konnte man allerdings nur mit Hilfe der rhetorischen Analyse des Textes erreichen, welche von der offiziellen Kirche im Jahre 1993 angenommen und als exegetische Methode für Wissenschaftler vorgeschlagen wurde ${ }^{33}$. Das ist auch ein illustrierendes Beispiel der Offenheit der Kirche für einige Neuheiten im Bereich der biblischen Hermeneutik. Genau um so etwas geht es im vierten Grundsatz des Lesens der Bibel: Die Leser der Bibel sollten für verschiedene hermeneutische und exegetische Neuigkeiten offen sein.

\section{Der fünfte Grundsatz:}

\section{Die Bibel sollte als eine Ganzheit gelesen werden}

Der Name Bibel hat griechische Wurzeln. Er stammt eigentlich aus zwei griechischen Worten, und zwar von $\beta v ́ \beta \lambda o \varsigma$ und $\beta \imath \beta \lambda$ íov. Der erste Begriff bedeutet Papyrus und der zweite, wörtlich übersetzt, bezeichnet ein Blatt oder eine Rolle. Das Wort $\beta u ́ \beta \lambda o \varsigma$ erinnert daran, welches Material in der Antike zum Schreiben

\footnotetext{
32 Vgl. R.T. France, The Gospel..., S. 251; J. Homerski, Ewangelia ..., S. 149-150.

${ }^{3}$ Vgl. D. Amilevičius, Nauji Biblijos tekstu literatūrinès analizès metodai: retorinè analizé, „Soter“ 1 (1999), S. 5-16.
} 
benutzt wurde. Das war eine Pflanze, Papyrus genannt, welche am Ufer des Nils wuchs. Aus ihr wurden nämlich $\beta \imath \beta \lambda$ íov, das heisst Papyrusblätter gemacht, welche zusammengelegt die sogenannten Papyrusrollen formierten. Sie wurden später normalerweise in die Stadt Byblos, ein damaliges Zentrum der Papyrusindustrie, gebracht. Im Laufe der Zeit wurde das Wort $\beta \imath \beta \lambda$ íov nicht nur für die Papyrusblätter und Papyrusrollen, sondern auch für den aufgeschriebenen Text benutzt. So begann $\beta$ i $\beta \lambda$ íov ebenfalls ein bestimmtes Buch oder mehrere Bücher zu benennen. Solche Fälle befinden sich ebenfalls in der Heiligen Schrift (1 Makk 12,9; 2 Makk 8,23bc). Doch in diesen Sätzen bezeichnet der Begriff $\beta \imath \beta \lambda$ íov nur einige Bücher der Heiligen Schrift. Für das Ganze der Bibel wurde er erst im IV. Jahrhundert nach Christus eingesetzt. Das war ein Verdienst des heiligen Johannes Chrysostomos (ca. 377-407). Er war der erste Mensch, der die ganze Heilige Schrift mit dem Namen Bibel nannte. Später übernahmen diese Bezeichnung auch latei-

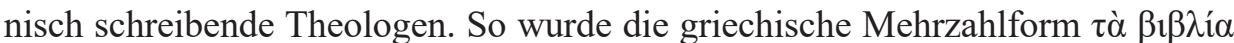
als lateinisches Lehnwort biblia übernommen und bekam auch Aufnahme in der europäischen Sprache. Anders gesagt, die Bibel bedeutet eigentlich die Bücher oder die Büchersammlung. Man könnte auch sagen, die Bibel ist eine kleine Bibliothek. Die katholische Variante der Heiligen Schrift besteht aus 73 Einzelbüchern. Normalerweise ist diese Sammlung auch mit dem Namen Kanon bekannt. Und dort haben die Bücher einen eigenen bestimmten Platz. Dasselbe gilt auch für die Kapitel jedes Buches. Sie wurden auch in einer gewissen Ordnung zusammengestellt. Das kann man auch von der Reihenfolge der Verse sagen: Ihre Plätze sind nicht zufällig. Deshalb lesend die Heilige Schrift muss man auf 1) den Kontext sowie auf 2) die Einheit des Alten und Neuen Testamentes achten.

\section{Kontext}

Das gesagte oder geschriebene Wort, nur für sich selbst genommen, ist weder wahr, noch falsch. Die Benennung bildet ja nicht die einzige Funktion der Sprache. Diese stellt auch nicht den Höhepunkt der Möglichkeiten des menschlichen Redens dar. Deshalb erfordert jeder Satz zumindest einen Substantiv und ein Verb, welche eigentlich die ursprüngliche prädikative sprachliche Einheit formieren, die etwas Bestimmtes bedeuten kann ${ }^{34}$. Mit anderen Worten, den endgültigen Sinn jedes Begriffes entscheidet nur sein Kontext. Dazu eine Illustration. Ein Atheist könnte sagen: Die Bibel leugnet die Existenz Gottes! Und als Beweis würde er Ps 14,1d zitieren, wo wirklich gesagt wird: „Es gibt keinen Gott“. Diese Aussage erlaubt jedoch nicht solche drastische Schlussfolgerung zu ziehen. So konnte in den Zeiten des Alten Testamentes nur der dumme Mensch sprechen. Deshalb ist die Aussage es gibt keinen Gott von einem davorstehenden Satz ein-

\footnotetext{
${ }^{34}$ Vgl. P. Ricoeur, Interpretacijos teorija. Diskursas irreikšmès perteklius, vert. R. Kalinauskaitè, G. Lidžiuvienè, Vilnius 2000, S. 13-14.
} 
geleitet: „Der Tor sagt in seinem Herzen“ (14,1c). Die Bedeutung jedes Wortes ist nur vom Kontext her zu vestehen.

\section{Einheit der zwei Testamente}

Die Grundlage der Schriften des Neuen Testamentes ist das Ereignis Jesus von Nazareth (1 Kor 15,3-5). Er ist die Kulmination und der Höhepunkt des Alten Testamentes (Mt 1,22-23; 2,5-6 etc.). Somit aber erhebt sich eine logische und auch konsequente Frage, die das Schicksal der Schrift des Alten Bundes und ihr Verhältnis zum Neuen Testament betrifft. Sie ist gleichzeitig eine der wichtigsten und archaischsten Fragen der christlichen Theologie ${ }^{35}$. Die Antworten darauf waren unterschiedlich. Es fehlte weder der Kritik noch überflüssiger Begeisterung, sowohl am Text des Alten als auch des Neuen Testamentes. Der berühmte Marcion (ca. 85-160) hat aus dem christlichen Kanon der Bibel das ganze Alte Testament gelöscht. Eigentlich erkannte er nur das Evangelium nach Lukas und neun von den vierzehn Briefen des heiligen Paulus an. Eine ganz andere Ansicht dazu hatten die sogenannten Ebioniten - eine christlich-jüdische Gruppe des Urchristentums. Sie haben nur das Alte Testament akzeptiert. Das Neue Testament, außer dem Evangelium nach Matthäus, galt ihnen nichts ${ }^{36}$.

Diese vorher genannten zwei Richtungen sind selbstverständlich nicht akzeptabel. Das geht klar aus dem Magisterium der Kirche hervor. Sie lehrt: Beide Testamente sind wichtig, gleichberechtigt und verbindlich. Und das Wichtigste ist: Beide sind und müssen von den Gläubigen gelesen, meditiert und studiert werden. Die Regel dazu klingt ziemlich einfach: Das Alte Testament muss man im Licht des Neuen und das Neue im Lichte des Alten ergründen (Dei Verbum, Nr. 16). Diese Wahrheit lässt sich mit einem Beispiel erklären. Im Buch Genesis liest man folgendes: „Dann sprach Gott: Lasst uns Menschen machen als unser Bild, uns ähnlich!“ (1,26ab). Das ist eines der wichtigsten anthropologischen Texte der Bibel. Die Heilige Schrift sprechend über Gott offenbart auch den Menschen, geschaffen nach seinem Bild. Er ist ein theomorphisches Wesen. Gott wurde eingeschrieben in seiner Definition. Ohne Gott erinnert der Mensch an eine Frage ohne Antwort oder einen Pilger ohne Strasse. Gott wollte jedoch den Menschen nicht nur nach seinem Bilde, sondern auch nach seiner Ähnlichkeit schaffen. Aber über die Realisierung dieses Projektes liest man nur folgendes: „Gott erschuf den Menschen als sein Bild, als Bild Gottes erschuf er ihn" (Gen 1,27a). Und wohin ist die Ähnlichkeit verschwunden? Das Alte Testament beinhaltet keine Antwort. Eines ist sicher: Gott wollte den Menschen nach seinem Bild und seiner Ähnlichkeit schaffen, aber er hat nur eins geschaffen - das Bild. Daraus ist die Schlussfolgerung offensichtlich: Der Mensch ist ein unvollendetes Werk. Das Geheimnis

\footnotetext{
${ }^{35}$ Vgl. A. Jacopozzi, Religijos filosofija, vert. R. Šerpytytè, Vilnius 1998, S. 15-16
}

${ }^{36}$ Vgl. J. Salij, Pytania ..., S. 53. 
dieser Vollendung des homo sapiens wurde erst in den Zeiten des Neuen Testamentes gelüftet. Das geschah nur durch die Menschwerdung des Sohnes Gottes, welcher als Bild Gottes $($ Kol 1,15) auch die schon im Alten Testament geplante Ähnlichkeit offenbarte. Dazu liest man im Neuen Testament verschiedene Texte. Einer von ihnen ist folgender: „Geliebte, jetzt sind wir Kinder Gottes. Doch ist noch nicht offenbar geworden, was wir sein werden. Wir wissen, dass wir ihm ähnlich sein werden, wenn er offenbar wird; denn wir werden ihn sehen, wie er ist" (1 Joh 3,2). Anders gesagt, nach der Absicht Gottes ist der Mensch, ein theomorphisches und unvollendetes Wesen (Bild), berufen aber Jesus Christus ähnlich zu sein (Ähnlichkeit), demzufolge eine christomorphische oder vergöttlichte Person zu werden, die Anteil hat am inneren Leben der heiligsten Dreifaltigkeit (1 Petr 1,3ff). Diese Wahrheit ist aber nur dann offensichtlich und verständlich, wenn beide Testamente zusammen gelesen werden ${ }^{37}$.

\section{Der sechste Grundsatz: \\ Die Bibel sollte man als Heilige Schrift lesen}

Auf den ersten Blick klingt diese Regel ziemlich seltsam. Die Bibel als Heilige Schrift lesen, was sollte das bedeuten? Folgende Gedanken: Das würde heissen, dass die Bibel als 1) göttliches (Heilige) und als 2) menschliches Wort (Schrift) gelesen werden sollte.

1. Die Bibel als menschliches Wort

Die Bibel wurde von verschiedenen Menschen, welche in unterschiedlichen Zeiträumen lebten, geschrieben. Sie hatten eigene Berufe und kamen aus diversen sozialen Schichten: Moses war ein ausgebildeter Jurist, Josua - ein militärischer Führer, David - ein poetisch und musikalisch begabter König, Salomon - ein weiser und in der Liebe erfahrener Herrscher, Amos - ein einfacher Hirte, Petrus - Fischer, Paulus - Rabbiner usw. Jeder von ihnen schrieb auf eigene Art und Weise, einige sogar mit grammatischen Fehlern und eigenen Ansichten. Aus diesem Grunde nämlich ist die Bibel ein wirkliches menschliches Wort, welches zum Erbe der Weltliteratur gehört. Deshalb lesend die Bibel müsste man diese Ebene obligatorisch beachten. Ohne die Einbeziehung dieser Ebene kann man die Bibel als Wort Gottes nicht ohne weiteres verstehen. Demgemäss muss man zuerst die Bibel als nur menschliches Wort betrachten und lesen. Und die Bibel als menschliches Wort lesen hiesse in ihr das literarische Kulturerbe zu sehen. Das wäre ein rein intellektuelles Lesen der Heiligen Schrift, dessen grundlegendes Ziel in der Verbreitung des allgemeinen Wissens und in der Befriedigung der natür-

${ }^{37}$ Vgl. B. Ferdek, Nasza ..., S. 45-76, 133. 
lichen Neugierde des Menschen bestehen würde. Jeder Christ sollte wenigstens einmal im Leben die ganze Bibel als ein Werk der schönen Literatur durchlesen. Das ist eine Art und Weise des Lesens der Bibel, welche man als Lektüre vom Brett zum Brett nennen kann oder, benutzend eine biblische Terminologie, könnte man sagen, das sei eine Lektüre der Bibel vom Buch Genesis bis zur Apokalypse des heiligen Johannes. Solche Lektüre würde ungefähr dreieinhalb Jahre dauern, wenn man jeden Tag ein Kapitel eines bestimmten Buches liest. Und wenn diese Zeit zuende ist, dann kann man eine andere Sprache wählen und noch einmal die Bibel in der Folge der nächsten dreieinhalb Jahre lesen und so weiter bis zum Ende des Lebens. Das ist, wie oben gesagt wurde, nur eine laische Art des Lesens der Bibel. Es geht hier nur darum, um bestimmtes Wissen zu erlangen und das schon Erreichte zu vertiefen. Dieses Wissen ist auch für das geistliche Leben notwendig. Es sollte helfen verschiedene biblische Geschichten oder Stellen miteinander zu verbinden, sowie die biblischen Motive in anderen Werken der weltlichen Literatur anzuerkennen. Ein kleines Beispiel. Es gibt ein berühmtes Gedicht des russischen Dichters Alexander Puschkin (1799-1837), welches den Titel Prophet trägt. Es wurde im Jahre 1826 geschrieben. Dieses Gedicht beinhaltet auch viele biblische Anspielungen, diese kann aber nur eine Person, welche die Bibel ziemlich gut kennt, erkennen. Am Anfang des Gedichtes liest man so: „Von geistigem Durst gequält, schleppte ich mich in der finsteren Wüste dahin, und ein sechsflügeliger Seraph erschien mir am Kreuzweg“". Die Worte der geistige Durst erinnern an eine Seligpreisung Jesu, welche vom Hungernden und Dürstenden nach Gerechtigkeit spricht (Mt 5,6). Die Aussage die finstere Wüste ist ein Symbol des Chaos und weist auf die Schöpfungsgeschichten des Buches Genesis hin, wo am Anfang der Schöpfung das Chaos herrscht $(1,2)$. Die Mitteilung der sechsflügelige Seraphim, der dem Dichter erschien, und dann im Fortlauf des Gedichtes ihm die sündige Zunge herausriss, deutet sicherlich die Berufung des Jesaja zum Propheten an, wo auch von Seraphinen und vom Reinigen der unreinen Lippen des Propheten die Rede ist $(6,1-7)$. Solche Anspielungen beinhaltet dieses Gedicht noch vielfach. Diese erkennt aber nur ein Leser, welcher die Bibel ziemlich gut kennt. Und zu dieser Erkenntnis gelangt man nur, wenn man die Bibel gern und oft liest.

\section{Die Bibel als göttliches Wort}

Die Bibel soll man nicht nur als einfaches Buch (Schrift) lesen, sondern auch als Wort Gottes (Heilige). Und als Wort Gottes lesen, sagend mit der Sprache der Kirchenväter, würde bedeuten sie als ein Brief Gottes, welcher an den Leser der Bibel persönlich gerichtet ist, zu sehen ${ }^{38}$. Um dieses Ziel zu erreichen, reicht jedoch die rein intellektuelle Anstrengung des Lesers nicht. Dazu ist ebenfalls wichtig die Teilnahme des gläubigen und liebenden Herzens. Solche Art

\footnotetext{
${ }^{38}$ Vgl. T. Jelonek, Matżeństwo i rodzina w Piśmie Świętym, Kraków 2007, S. 10.
} 
und Weise des Lesens der Bibel nennt man lectio divina, deren letztendliches Ziel im göttlichen Wissen, d. h. im Heil des Menschen steckt und welche ihn zu einer persönlichen Bindung mit Gott bringt. Jeder Christ sollte sich wirklich täglich mit dem Wort Gottes stärken, weil es die wichtigste Nahrung der Tugend des Glaubens ist $(\mathrm{Mt} 4,4)^{39}$. Dazu eine belehrende Illustration. Im 11. Kapitel des zweiten Buches Samuel wird von einem Ereignis aus dem Leben des berühmten David berichtet. Diese Begebenheit geschah ungefähr im X. Jahrhundert vor Christus. In der damaligen Zeit war David König des ganzen auserwählten Volkes. Sein Regieren war verhältnismässig erfolgreich. Das israelitische Volk hatte ihn gern und diente ihm begeistert. David erweiterte ja die Grenzen seines Landes und führte ehrlich seine königliche Funktion aus ${ }^{40}$. Es gab natürlich auch einige Probleme, besonders auf dem politischen Gebiet, und zwar wegen der Führung von Kriegen. Von einem davon liest man nämlich am Anfang des erwähnten Abschnittes. David schickte sein Heer in das Land der Ammoniter aus. Es belagerte die Stadt Rabba. Doch der König selbst blieb in Jerusalem. Eines Tages spazierend auf dem Dach seines Palastes sah er eine schöne Frau. Er liess sie zu sich kommen und ungeachtet dessen, dass sie die Ehefrau Urijas war, ,schlief“ er mit ihr und machte sie schwanger. Als David das erfuhr, befahl er ihren Ehemann zu töten. Und so geschah es. Solches Handeln des Königs gefiel Gott nicht. Deshalb schickte er seinen Propheten Natan zu David, dass er ihn zur Bekehrung anrege. Das gelang dem Propheten. David hat sich bekehrt (2 Sam 12,1-25; Ps 51) ${ }^{41}$.

Auf den ersten Blick hat diese Begebenheit nur eine geschichtliche Bedeutung. Das klingt wie eine interessante Geschichte, welche nichts mit dem heutigen Leser der Bibel zu tun hat. Doch ist das nur der erste Eindruck, weil die Bibel nicht nur menschliches (Schrift), aber auch lebendiges Gottes Wort (Heilige) ist. Und als solche erzählt sie nicht von uralten Zeiten, sondern spricht zum heutigen und auch vom heutigen Menschen. Deshalb müsste man diese Begebenheit mit dem König David noch einmal untersuchen und nach ihrem tieferen Sinn fragen.

Als erste Sache fällt auf, was am Anfang des erwähnten Textes steht, und zwar folgendes: „Um die Jahreswende, zu der Zeit, in der die Könige in den Krieg ziehen, schickte David Joab mit seinen Knechten und ganz Israel aus [...]" (2 Sam 11,1a). Hier wird von einigen damaligen Kriegssitten gesprochen. Er wurde nur in fest verordneten Zeiten geführt, das heisst nach der Aussaat oder nach der Ernte. Die Ursache dessen bestand darin, dass damals noch keine professionelle Armee bestand. Zu ihr gehörten Leute, die eigentlich andere Berufe hatten. Dieser Text nennt noch eine andere Besonderheit der damaligen Führung des Krieges, und zwar erwähnt er, dass normalerweise auch die Könige in den

\footnotetext{
${ }^{39}$ Vgl. H.U. von Balthasar, W petni wiary, tłum. J. Fenrychowa, Kraków 1991, S. 378.

${ }^{40}$ Vgl. T. Schwartz, Auch ..., S. 34.

${ }^{41}$ Vgl. ebd., S. 41-42.
} 
Krieg mit ihren Heeren zogen. David achtete auf die Kriegszeiten, doch wollte er diesmal nicht mit seinem Heer mitziehen. Er blieb in seinem Palast in Jerusalem (2 Sam 11,1b). Die Bibel gibt keinen Grund dafür an. Deshalb könnte man sagen, dass David ganz einfach faulenzte. Das war nämlich eine der Grundlagen seiner Sünden. Der Mensch ist ein begrenztes Wesen. Er muss ausruhen (Ex 20,8-11). Doch zwischen dem Ausruhen und Faulenzen besteht ein grosser Unterschied (Spr 13,4). Im Leben eines Christen muss es immer eine Zeit des Ausruhens geben (Mk 6,31), nicht aber für die Faulheit, weil diese letztere oft genug eine Gelegenheit zum Sündigen ist (Spr 10,4; 15,19). Der Anfang der Sünden Davids steckte aber nicht nur in seiner Faulheit. Dazu trugen auch seine Augen bei. Er sah von seinem Palast aus eine Frau. Sie war schön (2 Sam 11,2). David schaute und was er sah war prachtvoll. Das alles erinnert an das Handeln des ersten Menschen im Garten Eden. Eva schaute ebenfalls auf den verbotenen Baum und sah, dass er eine Augenweide war $($ Gen 3,6). Im Leben der heutigen Menschen ist es oft ähnlich. Viele ihrer Sünden beginnen mit dem Schauen (1 Joh 2,16).

Die nächste beachtliche Sache ist diese, dass David die schöne Frau erblickend sich sofort erkundigte, wer sie ist. Es wurde ihm geantwortet: Das ist Batseba, die Gattin des Hetiters Urija (2 Sam 11,3). Ungeachtet dessen schickte David seinen Diener nach ihr und liess sie zu sich in den Palast herbringen (2 Sam 11,4). Damit will die Bibel sagen, dass die Sünde andere Menschen einbezieht (Ps 50,18).

Diese Begegnung war damit nicht zuende. Die Folge dessen war die Schwangerschaft der Frau. Davon erfuhr auch David, weil Batseba ihm das ausrichten liess: „Ich bin schwanger“ (2 Sam 11,5b). Ob der König das wollte? Sicher nicht! $\mathrm{Ob}$ er das plante? Bestimmt nicht! Aber die Schwangerschaft war trotzdem da! Der Anfang des Lebens ist immer ein Geheimnis (2 Makk 7,22). Und dadurch will die Heilige Schrift zeigen, dass der Mensch nicht alle Folgen seiner Sünden voraussehen kann. Wer den Weg der Sünde wählt, der erlebt an ihr - früher oder später - eine gewisse Überraschung, doch nicht positive (Ps 1,6).

Und welche war Davids Reaktion auf die Schwangerschaft Batsebas? Ganz listig und eiskalt ${ }^{42}$. Er hat sich entschlossen ihren Gatten Urija, welcher im Krieg war, nach Hause rufen zu lassen. Und als er kam, begann er ihn nach dem Zustand des Krieges zu befragen. Das war natürlich ganz logisch. Damals gab es keine heutige mediale Mittel. Doch es ging dem David nicht nur darum. Sein Plan reichte weiter. Er wollte nämlich den Urija nach Hause schicken, deshalb sagte er ihm: „Geh in dein Haus hinab und wasch dir die Füße!“ (2 Sam 11,8b). Damit war nicht nur eine hygienische Tätigkeit gemeint, sondern auch ein geschlechtlicher Verkehr. Die Idee Davids war: Urija sollte nach Hause gehen und mit Batseba „schlafen“, das hiesse Vater des schon begonnenen Lebens in ihrem Mutterschoss

${ }^{42}$ Vgl. T. Schwartz, Auch ..., S. 41-42. 
zu sein ${ }^{43}$. Dieser Plan gelang aber nicht, weil damals in Kriegszeiten gewisse Regeln galten, und eine davon verbot geschlechtliche Kontakte, damit Krieger in der sogenannten rituellen Reinheit verblieben. Urija handelte danach, deshalb legte er sich vor das Tor des königlichen Palastes, ohne dass er in sein Haus ging (2 Sam $11,9)^{44}$. Als David sah, dass der Plan nicht gelang, wechselte er seine Strategie. Er rief Urija erneut und gab ihm Alkohol zu trinken. David war ein kluger Mann. Er wusste, was mit einer nüchternen Person nicht erreichbar ist, das kann man mit einem Betrunkenen machen (Gen 19,30-38). Aber auch diese Absicht misslang. Der Hetiter, obwohl betrunken, blieb der Sitte treu. Der Preis für diese Treue war sehr hoch. Es kostete ihm sein Leben, weil David einen Brief schrieb und diesen durch Urija an Joab schickte: Er sollte Urija in den heftigsten Kampf schicken, sodass er getroffen würde und den Tod fände (2 Sam 11,15). Und so geschah es (2 Sam 11,17). Dadurch zeigt die Bibel, dass der Sünder immer versucht seine Sünde zu verstecken (Spr 28,13). Damit er das erreichen kann, muss er noch eine weitere Sünde begehen, doch immer grössere und schwerere. Im Falle Davids verbarg der Mord an Urija den Ehebruch mit Batseba. Im Leben der heutigen Menschen ist es ähnlich. Sie versuchen ebenfalls ihre eigene Schuld zu verbergen.

Es wurde schon gesagt, dass am Anfang der Sünde Davids seine Augen standen, und das, was er sah war schön. Diese Schönheit Batsebas hatte selbstverständlich einen estetischen Sinn. Es war die Schönheit ihres Leibes. Doch heisst das hebräische hier benutzte Wort ט nicht nur physische Schönheit. Es bedeutet auch etwas Gutes (Gen 1,4). Deshalb könnte man die Schönheit Batsebas auch auf andere Weise auslegen, und zwar, ginge es hier darum, dass David, welcher die schöne Frau erblickte, dachte: Das Zusammensein mit ihr würde gute Früchte bringen. David war in Wirklichkeit in einer schwierigen Situation. Er hat sein Heer ausgeschickt und hatte keine Information über die Lage des Krieges. Mit dieser Frage beschäftigte er sich ganz sicher, weil wenn das Heer Erfolg hätte, dann würde seine königliche Autorität in den Augen des israelitischen Volkes wachsen. Andernfalls, wenn das Heer eine Niederlage erführe, dann würde seine Popularität fallen. Anders gesagt, David machte sich Sorgen um sein Ansehen in den Augen des Volkes. Um solche Gedanken zu verjagen, entschied er sich für eine „Erholumng“ mit Batseba. Diese Art und Weise des Denkens, dass die Sünde gute Früchte bringt, ist allgemein zwischen Menschen üblich. Jeder Sünder, welcher die Gebote Gottes bricht, denkt ähnlich. Er hofft, dass das Nichtbeachten der Gebote Gottes ihn von verschiedenen Begrenzungen erlösen wird und ihm

${ }^{43}$ Vgl. J. Blenkinsopp, 1 and 2 Samuel, in: A New Catholic Commentary on Holy Scripture, ed. by R.C. Fuller, L. Johnston, C. Kearns, Nashville-Camden-New York 1984³, S. 305-327, hier: S. 322-323.

${ }^{44}$ Vgl. J. Blenkinsopp, 1 and ..., S. 322-323; A.F. Campbell, J.W. Flanagan, Pierwsza i Druga Księga Samuela, in: Katolicki komentarz biblijny, red. R.E. Brown, J.A. Fitzmyer, R.E. Murphy, red. wyd. pol. W. Chrostowski, (Prymasowska Seria Biblijna), Warszawa 2004², S. 260. 
etwas Gutes bringt. Doch das ist eine falsche Perspektive. Der Fall David verbildlicht das ganz deutlich, besonders dann, wenn man das liest, was im 12. Kapitel des erwähnten Buches steht. Dort wird von seiner Begegnung mit dem Propheten Natan erzählt, welcher ihn im Namen Gottes zur Bekehrung anregte. Jedoch Natan fügte noch folgendes hinzu: „Du hast den Hetiter Urija mit dem Schwert erschlagen [...]. Darum soll jetzt das Schwert auf ewig nicht mehr von deinem Haus weichen" (2 Sam 12,9b-10a). Und wirklich ist das weitere Leben Davids von Gewalt gezeichnet. Er selbst litt, aber auch seine Familie, in der sogar Fälle von Mord geschahen, wie zum Beispiel der Tod des geliebten Sohnes Abschalom (2 Sam 18,9-15) ${ }^{45}$. Ob David nach solchem Schicksal verlangte? Sicher nicht. Er wartete nur auf positive Wirkungen. Doch die Sünde wirkt wie ein Bumerang, das heisst, sie trifft immer auch den Sünder selbst. Dieses hier erwähnte Beispiel weist deutlich darauf hin, dass die Bibel nicht nur spannende Geschichten (Schrift) erzählt. Diese beinhalten auch eine überzeitliche Botschaft, die von der Inspiration des Heiligen Geistes stammt (Heilige).

\section{Nachwort}

Im Jahre 1993 wurde von der Päpstlichen biblischen Kommission das Dokument zum Thema der Interpretation der Bibel in der Kirche herausgegeben. Es beschäftigte sich mit verschiedenen damals aktuellen hermeneutischen und exegetischen Fragen, vor allem auf der wissenschaftlichen Ebene. Doch die pastorale Seite dieser Problematik wurde darin auch nicht ausgeklammert: Die Seelsorger sollten ebenfalls die Heilige Schrift den Gläubigen in verständlicher Art und Weise nahebringen. Der vorliegende Artikel soll ein Beitrag dazu sein. In ihm wurden die hauptsächlichen hermeneutischen Grundsätze (literarische und theologische) der Kirche zum Lesen der Bibel in der Sprache der „Unmündigen“ dargestellt. Der erste - die Bibel wurde in keiner der heutigen Sprachen geschrieben - regt zum Studium der Originalsprachen der Heiligen Schrift an. Der zweite - die Bibel wurde nicht von heutigen Autoren geschrieben - lädt zum Kennenlernen der Geschichte und Kultur des Altertums des Nahen Ostens ein. Der dritte - die heutigen Menschen sind nicht die ersten Leser der Bibel — erinnert daran, dass die Heilige Schrift vor allem ein Buch des Glaubens ist und zum Benutzen aus dem grossen Schatz der patristischen Interpretation der Bibel anregt. Der vierte - die heutigen Menschen werden nicht die letzten Leser der Bibel sein - fordert zur ständigen und unaufhörlichen Vertiefung der Geheimnisse des Wortes Gottes, sowie zur vernünftigen Offenheit für exegetische Neuigkeiten auf. Der fünfte - die Bibel sollte als eine Ganzheit gelesen werden - unterstreicht, dass die biblischen

${ }^{45}$ Vgl. J. Blenkinsopp, 1 and ..., S. 323; A.F. Campbell, J.W. Flanagan, Pierwsza ..., S. 260. 
Texte helfen sich gegenseitig zu verstehen. Der sechste - die Bibel sollte man als Heilige Schrift lesen - empfiehlt in der Heiligen Schrift nicht nur das menschliche Wort zu suchen, was ja offensichtlich ist, sondern diese auch und vor allem als Wort des Herrn zu betrachten (Am 8,12). Solche Grundsätze sollten den Seelsorgern helfen, den Gläubigen in der ihnen verständlichen Sprache die Bibel zu vermitteln, aber auch den Gläubigen selbst eine selbständige exegetische Kapazität der Heiligen Schrift einprägen. Normalerweise symbolisiert die Zahl sechs in der Bibel die Unvollkommenheit, weil ihr bis zur Sieben, welche das Symbol der Vollkommenheit ist, die Eins fehlt. Diese hier fehlende Eins (sechs Grundsätze) ist die Empfehlung zur Lektüre der Bibel. Das ist der einzig richtige Weg, der zur Kenntnis der Heiligen Schrift führt und alle exegetischen Tätigkeiten ermöglicht.

\title{
The principles of Catholic biblical hermeneutics in "the language of infants". A contribution to the 25th anniversary of the Document of the Pontifical Biblical Commission "The Interpretation of the Bible in the Church"
}

\section{Summary}

\begin{abstract}
Almost 25 years ago, the Pontifical Biblical Commission issued the document "The Interpretation of the Bible in the Church". It dealt with various at that time current hermeneutical and exegetical questions, especially on the scientific level. However, the pastoral ministry side of this matter was not excluded. The pastors - as the document states — should also bring the Scriptures for the faithful in a comprehensible way (Chap. IV, Art. C, No. 3). But how to do it practically? The document does not expand this thread. This article is a small contribution to the topic. In it, the main hermeneutical principles of the Catholic Church for reading the Bible in the language of infants (Mt 11,25) are presented.
\end{abstract}

\section{Keywords}

Bible, Pontifical Biblical Commission, hermeneutics, exegesis, interpretation, pastoral ministry 


\section{Zasady katolickiej hermeneutyki biblijnej ,językiem prostaczków”. Przyczynek do upamiętnienia 25. rocznicy opublikowania dokumentu Papieskiej Komisji Biblijnej „Interpretacja Pisma Świętego w Kościele”}

\section{Streszczenie}

Ponad 25 lat temu Papieska Komisja Biblijna wydała dokument pod tytułem „Interpretacja Pisma Świętego w Kościele”. Został on poświęcony ówczesnym naukowym kwestiom hermeneutycznoegzegetycznym. Niemniej jednak duszpasterska strona tego zagadnienia nie została pominięta. Duszpasterze powinni także w dostępny sposób przybliżać Pismo Święte wszystkim wiernym (rozdz. IV, art. C, nr 3). Ale jak to zrealizować praktycznie? Dokument nie rozwija szczegółowo tego tematu. Niniejszy artykuł podejmuje dane wezwanie, przedstawiając główne hermeneutyczno-biblijne zasady Kościoła Katolickiego ,językiem prostaczków” (Mt 11,25).

\section{Słowa kluczowe}

Biblia, Papieska Komisja Biblijna, hermeneutyka, egzegeza, interpretacja, duszpasterstwo

\section{Bibliographie}

Amilevičius D., Nauji Biblijos tekstu literatūrinès analizès metodai: retorine analizé, „Soter“ 1 (1999), S. 5-16.

Angerstorfer A., Harmening D., Klöckener M., Alphabet, in: Lexikon für Theologie und Kirche, hrsg. v. W. Kasper u. a., Bd. 1, Freiburg-Basel-Rom-Wien 1993³, S. 427429.

Auerbach E., Mimesis. Tikrovès vaizdavimas Vakaru pasaulio literatūroje, vert. A. Gailius, Vilnius 2003.

Augustin, Lectures or Tractates on the Gospel According to the St. John, transl. and ed. by J. Gibb, J. Innes, Grand Rapids 1983.

Balthasar H.U. von, W petni wiary, tłum. J. Fenrychowa, Kraków 1991.

Blenkinsopp J., 1 and 2 Samuel, in: A New Catholic Commentary on Holy Scripture, ed. by R.C. Fuller, L. Johnston, C. Kearns, Nashville-Camden-New York 1984³ , S. 305 327.

Brown R.E., An Introduction to the New Testament, (The Anchor Bible Reference Library), New York-London-Toronto-Sydney-Auckland 1997.

Campbell A.F., Flanagan J.W., Pierwsza i Druga Ksiegga Samuela, in: Katolicki komentarz biblijny, red. R.E. Brown, J.A. Fitzmyer, R.E. Murphy, red. wyd. pol. W. Chrostowski, (Prymasowska Seria Biblijna), Warszawa 2004², S. 242-263.

Croatto S., Uruk, in: Enciclopedia della Bibbia, a cura di A. Díez Macho, S. Bartina, vol. VI, Torino-Leumann 1971, S. 1067-1070. 
Dikevičius D., Dél Vilniaus šv. Juozapo kunigu seminarijos atkūrimo dvidešimtmetį, red. D. Dikevičius, I. Gudauskienè, (Bibliotheca Sancti Josephi 4), Vilnius 2014, S. 69-74.

Dzikiewicz D., Die revidierte Ausgabe der Einheitsübersetzung. Einige Beispiele verpasster Korrekturmöglichkeiten, „Studia Theologica Grodnensia“ 12 (2018), S. 89-102.

Fabris R., Giovanni, (Commenti biblici), Roma 1992.

Ferdek B., Nasza Siostra — Córa i Matka Pana. Mariologia jako przestrzeń syntezy dogmatyki, (Biblioteka Diecezji Świdnickiej 13), Świdnica 2007.

France R.T., The Gospel of Matthew, (The New International Commentary on the New Testament), Grand Rapids-Cambridge 2007.

Gamble H.Y., Canon. New Testament, in: The Anchor Yale Bible Dictionary, ed. by D.N. Freedman, vol. I, New Haven-London 2008, S. 852-861.

Harrington D.J., The Gospel of Matthew, (Sacra Pagina 1), Collegeville 1991.

Homerski J., Ewangelia wedtug św. Mateusza. Wstęp, przekład z oryginatu, komentarz, (Pismo Święte Nowego Testamentu: III/1), Poznań-Warszawa 1979.

Huesman J., Judges, in: A New Catholic Commentary on Holy Scripture, ed. by R.C. Fuller, L. Johnston, C. Kearns, Nashville-Camden-New York 1984³ , S. 294-302.

Jacopozzi A., Religijos filosofija, vert. R. Šerpytyte, Vilnius 1998.

Jaeger H., Wäsch M., Das Buch der Superlative, in: Die Bibel. Daten. Fakten. Wissenswertes, Kurzgefasst, hrsg. v. H. Jaeger, M. Wäsch, Dillenburg 2013², S. 7-8.

Jelonek T., Malżeństwo i rodzina w Piśmie Świętym, Kraków 2007.

Knoch O.B., Scholtissek K., Bibel. VIII. Bibelübersetzungen. 3. Mittelalterliche, neuzeitliche u. moderne europäische Übersetzungen, in: Lexikon für Theologie und Kirche, hrsg. W. Kasper u. a., Bd. 2, Freiburg-Basel-Rom-Wien 1994³, S. 388-398.

Kramer S.N., Istorija prasideda Šumere. Trisdešimt devyni dalykai, pirma karta paminèti rašytineje istorijoje, vert. A. Jurašius, Vilnius 2015.

Kudasiewicz J., Witczyk H., Zuberbier A., Hermeneutyka biblijna, in: Stownik teologicz$n y$, red. A. Zuberbier, Katowice 1998², S. 195-198.

Kuhn H. W., Anathema, in: Dizionario Esegetico del Nuovo Testamento, a cura di H. Balz, G. Schneider, trad. R. Chiavarino, V. Gatti, E. Riboldi, vol. I, Brescia 1995, S. 213-214.

Maceina A., Daiktas ir žodis. Lietuviu kalbos filosofija, Vilnius 1998.

Maceinienė T., Pradžioje buvo Žodis...: pokalbiai su Antanu Maceina-Jasmantu apie poezija, Vilnius 2004.

Mannucci V., Biblia come Parola di Dio. Introduzione generale alla Sacra Scrittura, (Strumenti 17), Brescia $1989^{10}$.

Międzynarodowa Komisja Teologiczna, Interpretacja dogmatów, in: Od wiary do teologii. Dokumenty Międzynarodowej Komisji Teologicznej 1969-1996, red. J. Królikowski, Tarnów 2000, S. 273-302.

Miller S.M., Huber R.V., Historia Biblii. Dzieje powstania i odczytania Pisma Świętego, tłum. E. Czerwińska, (Przewodniki chrześcijańskie), Warszawa 2005. 
Paciorek A., Wstęp ogólny do Pisma Świętego, (Academica 17), Tarnów $1999^{2}$.

Pettinato G., I Sumeri, (Orizzonti della storia), Milano 1991.

Ricoeur P., Interpretacijos teorija. Diskursas ir reikšmès perteklius, vert. R. Kalinauskaitè, G. Lidžiuvienè, Vilnius 2000.

Rubinkiewicz R., Historia egzegezy, in: Wstęp ogólny do Pisma Świętego, red. J. Szlaga, Poznań-Warszawa 1986, S. 276-287.

Rupnik M.I., Perèjimo kultūra, Vilnius 2001.

Russell D.R., St John, in: A New Catholic Commentary on Holy Scripture, ed. by R.C. Fuller, L. Johnston, C. Kearns, Nashville-Camden-New York 1984³ , S. 1022-1074.

Salij J., Pytania nieobojętne, Kraków 1986.

Schniedewind W.M., How the Bible Became a Book. The Textualization of Ancient Israel, Cambridge 2005.

Schwartz T., Auch Jesus hatte schlechte Laune. Überraschendes aus der Bibel, FreiburgBasel-Wien 2017.

Stiller R., Przed nami szedt Gilgamesz, in: Gilgamesz. Epos babiloński i asyryjski ze szczątków odczytany i uzupetniony także pieśniami szumerskimi przez Roberta Stillera, Kraków 20164, S. 111-153.

The Revised Standard Version of the Bible: Catholic Edition, 1965, www.biblegateway. com [Abruf: 16.02.2019].

Vorgrimler H., Naujasis teologijos žodynas, vert. G. Žukas, Kaunas 2003.

Weimar P., Pismo, in: Praktyczny słownik biblijny, red. A. Grabner-Haider, tłum. T. Mieszkowski, P. Pachciarek, Warszawa 1995, S. 965-966.

Ziółkowski Z., Spotkania z Biblią, Poznań 1971². 